\title{
DEVELOPMENT AND TESTING OF STAND MODELS FOR DOUGLAS FIR AND LODGEPOLE PINE ${ }^{1}$
}

\author{
By R. M. NEWNHAM and J. H. G. SMITH ${ }^{2}$
}

\begin{abstract}
Methods used in the development and testing of stand models for Douglas fir and lodgepole pine are described briefly. Influence of spacings from 3.3 to 19.8 feet on number of trees per acre, basal area per acre, and average d.b.h. is shown graphically for Douglas fir. The importance of knowing distribution as well as amount of mortality is stressed and illustrated. Use of the model for studying thinning is described.

Study of a lodgepole pine model, which also includes tree height and volume per acre, suggests that the general approach based on crown width and d.b.h. of open-grown trees could be applied to other species. Because of the ease and speed of manipulation of these models they could become an important operational and research technique.
\end{abstract}

\section{INTRODUCTION}

Stand models are needed to facilitate use of data on individual trees to forecast development under many conditions of potential interest in forest management. The mathematical models described here can be used on an I.B.M. 7040 electronic computer to simulate growth of stands under various spacings and thinning regimes, as well as with differing kinds and amounts of mortality. When management objectives have been defined it is possible to determine the relative merits of each with a few minutes of analysis on an appropriate computer. Decisions that would require 100 years of field observation can be made with confidence by computer analyses of a limited amount of data in a very short time.

Unifying concepts derived from study of crown development were described by Smith (1963). Problems of forecasting stand development from measurements on individual trees were outlined by Smith (1964). Newnham (1964) described in detail his development of a stand model for Douglas fir Pseudotsuga menziesii (Mirb.) Franco and provided a computer program which can be manipulated and modified to test many alternatives. After developing his model for Douglas fir Newnham improved it further for analysis of lodgepole pine Pinus contorta Dougl.

\footnotetext{
${ }^{2}$ Research Paper No. 66, Faculty of Forestry, The University of British Columbia, Vancouver 8, B.C. Financial support in the form of an Extramural Research Grant by the Canada Department of Forestry is gratefully acknowledged.

a Dr. Newnham was granted his Ph.D. by the University of British Columbia, October, 1964, and now is employed in the Forest Research Branch of the Department of Forestry, Ottawa, Ont. Dr. Smith is a Professor in the Faculty of Forestry, U.B.C.
} 
Douglas fir is the most valuable and widely planted tree species in British Columbia. Lodgepole pine now is being used for lumber and will be used for manufacture of pulp and paper in very large quantities in the immediate future. Improved knowledge of stand management is needed for both species and use of electronic computing techniques can provide forest managers with many valuable answers in a short period of time.

\section{Douglas Fir}

\section{METHODS}

The development and testing of his Douglas fir model has been reported by Newnham (1964). It is based upon the relationships between crown width and d.b.h. of open-grown trees, and between d.b.h. and total age. D.b.h. growth of each tree is assumed to be that of open-grown trees until "competitive" crowns overlap. D.b.h. growth then is reduced for each 5-year period by an amount depending upon the degree of competition. Degree of competition is assumed to be described adequately by the sum of the "angles of intersection" of the crowns of trees located up to 8 times the initial planting distance from each tree tested. The model uses square spacing and starts with an initial matrix of 225 trees $(15 \times 15)$ which is repeated in the model to eliminate edge effect. The program studies each tree in turn and increases tree d.b.h. every 5 years in proportion to its freedom from competition up to an amount equivalent to open-growth rates. If the 5-year periodic growth rate falls below a specified percentage the tree is assumed to have died. The model was tested repeatedly until its calculated values (except for $3.3 \times 3.3 \mathrm{ft}$.) fell within the limits of the most commonly used yield tables for Douglas fir.

The model gives the following information at five-year intervals of age from 10 to 100: D.b.h. distribution of live trees and previous five-year mortality, total number of trees, mean d.b.h., basal area per acre, periodic increment, mean annual increment, and other pertinent statistics. The d.b.h. of each tree being tested in the model can be printed out as required.

Tests of various alternatives studied by Newnham (1964) are illustrated in Figs. 1-5. Figure 1 includes spacings at 3.3-foot intervals from 3.3 to 19.8 , and numbers of trees per acre, average d.b.h., basal area per acre, as well as frequency distributions of diameter for 9.9-foot spacing from ages 20 to 100 . With the exception of values for the 3.3-foot spacing, which are too high, Figure 1 gives an excellent picture of the influence of initial spacing on stand development.

The distribution of mortality following planting or seeding is often of as much importance as the amount of mortality. On the one hand clumped mortality ${ }^{3}$ results in loss of yield in direct proportion to the area on which trees died. On the other hand initial mortality could be as high as 75 per cent without influencing yield if the dead trees were systematically distributed (Smith, Ker, and Csizmazia, 1961). The importance of amount and distribution of mortality increases greatly if the stand is established at an initially wide spacing. Figure 2 illustrates an initial diameter matrix with 10 per cent binomial distribution of mortality following planting. It also

\footnotetext{
${ }^{3}$ Newnham has prepared a program for calculation of tables for the negative binomial distribution which is available from the U.B.C. Faculty of Forestry.
} 

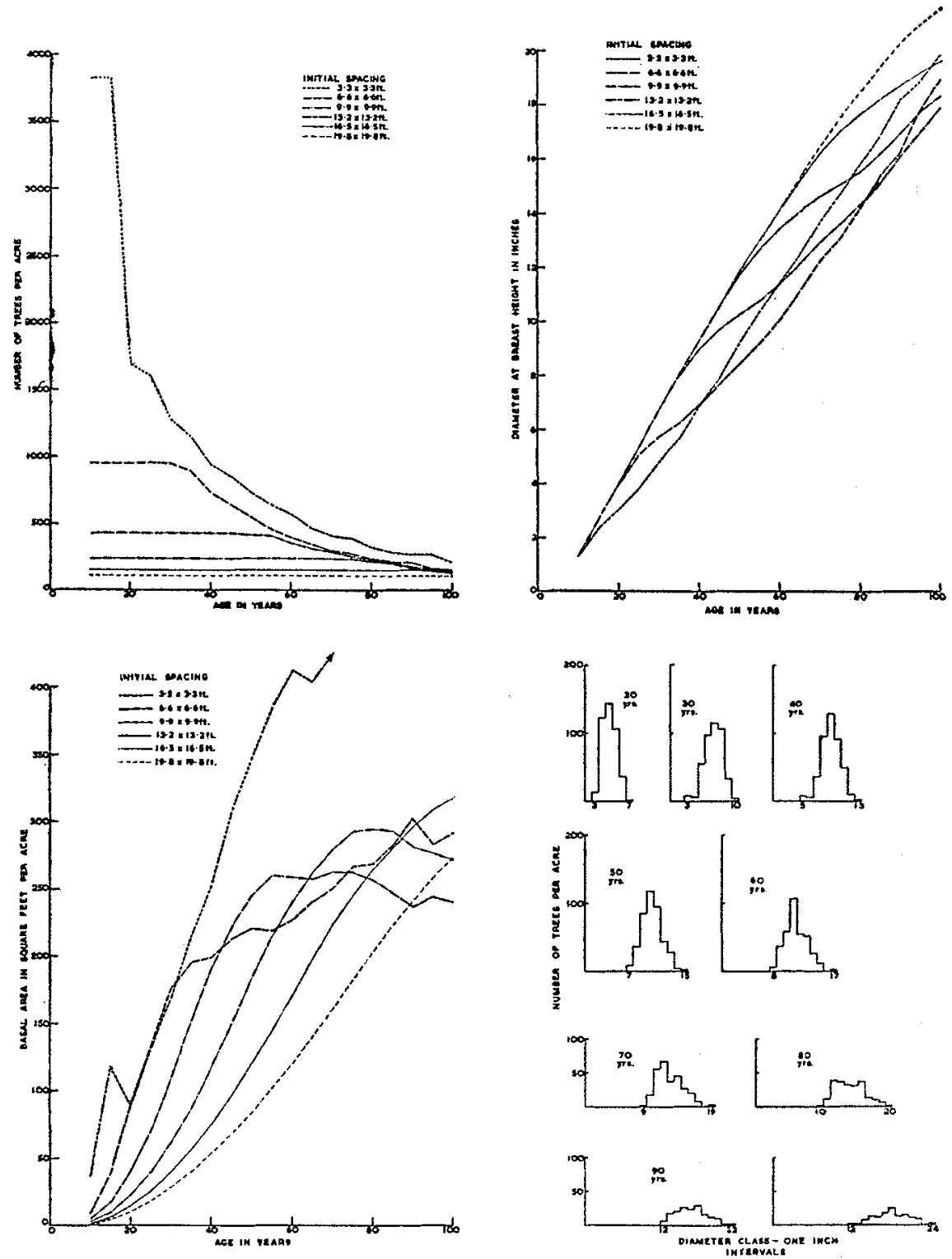

FIGURE 1. Influence of initial spacing on number of trees per acre, diameter at breast height, and basal area per acre for ages 10-100. Frequency distribution of D.b.h. is shown at various ages for the $9.9^{\prime} \times 9.9^{\prime}$ spacing. 
DECEMBER, 1964

INITIAL DIAMETER MATRIX
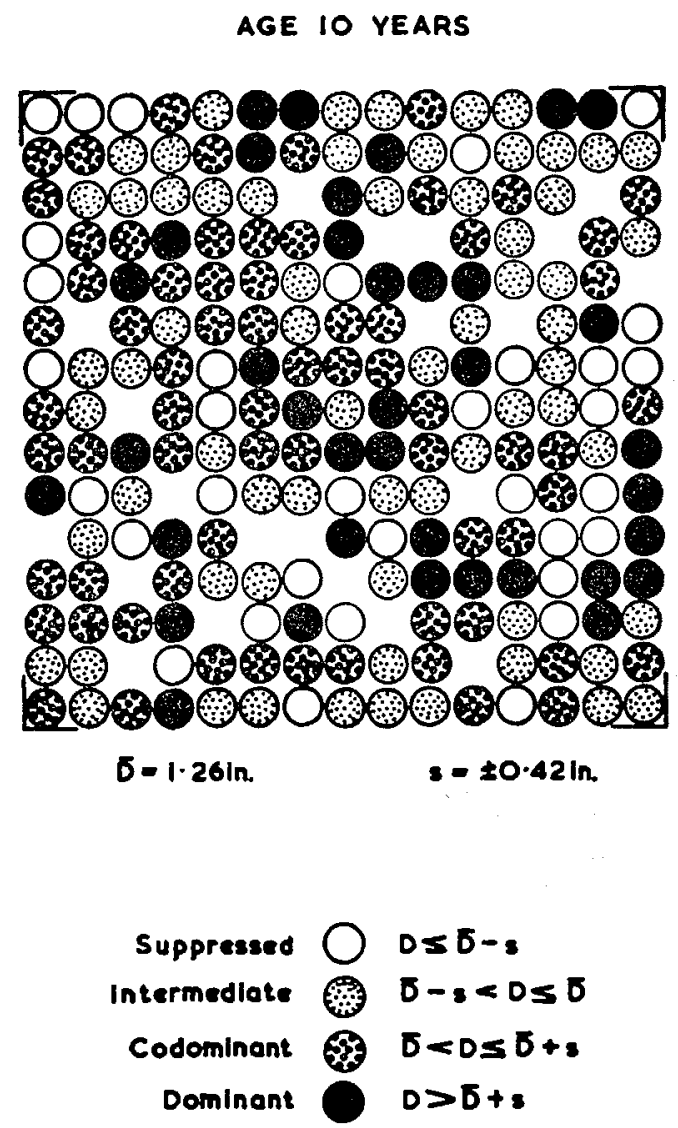

SCALE

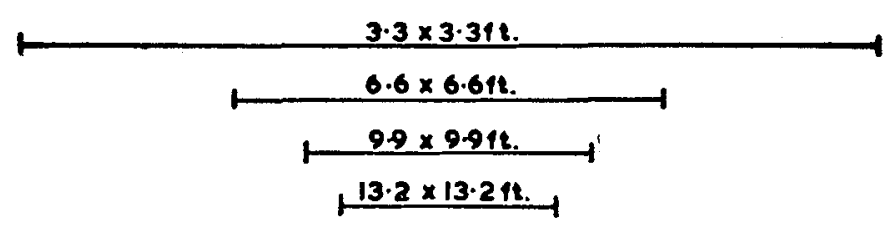

FIGURE 2. Initial D.b.h. matrix with 10 per cent binomial distribution of mortality following planting and legends for crown class and scale at four spacings for Figs. 2 and 3. 

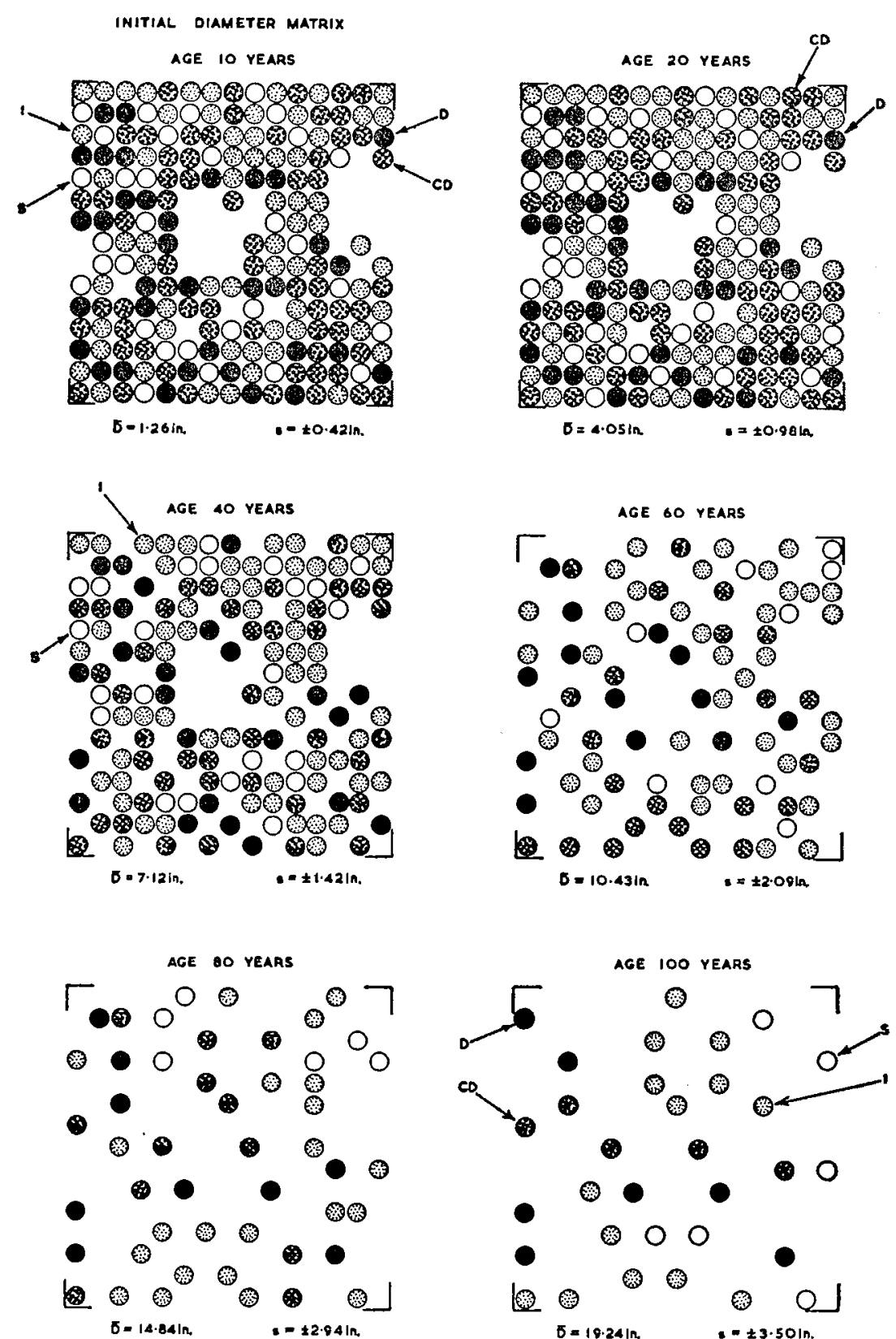

FIGURE 3. Development of a stand which suffered from two randomly located infection centers with clumped mortality totalling 14 per cent of the trees at age 10 
shows an arbitrary segregation of the stand into crown classes which are based upon the standard deviation of d.b.h. Figure 3 traces the development of a stand which suffered from two randomly located infection centers with clumped mortality totalling 14 per cent of the trees at age 10 . By age 60 most of the effect of this initial loss had disappeared and by age 100 the model shows no trace of the original pattern of mortality. The effects of several kinds and amounts of mortality on trees planted at an initial spacing of 9.9 feet are shown in Figure 4.

Although thinning could be studied subjectively by manual deletion of tree data cards after consideration of the size and distribution of each tree surviving at the end of each 5-year period, it is more convenient to define the trees to be removed objectively. In Figure 5 the results of removing at 10 -year intervals all trees smaller than one standard deviation below the mean d.b.h. are expressed in terms of number of trees and basal area per acre for 6.6-foot initial spacing.

Site quality was studied by varying the average size of trees used in the initial matrix. Height can be obtained from a regression equation given by Newnham (1964) in terms of d.b.h., (d.b.h.) $)^{2}$, and basal area per acre.

\section{Lodgepole pine}

The model is basically the same as that described for Douglas fir except that new data on crown width and d.b.h. growth of lodgepole pine were used. Much of the information came from a study by Bailey (1964) and from the basic data used by Dahms (1964). Unlike the variable factors used for Douglas fir, a fixed amount (two feet) is deducted from the calculated crown width to give the "competitive" crown width regardless of age or size of tree.

Height estimation of individual trees has been included in the model by use of a regression equation based on d.b.h., (d b.h. $)^{3}$, and basal area per acre. Volume per acre is calculated in total cubic feet by means of the combined variable formulae of Smith and Breadon (1964). The program prints out the average height of live and of dead trees for each five-year period and also gives the total volume as well as the volume of trees 6 inches and larger in d.b.h. Spacings tested include 3.3, 6.6, 9.9, and $13.2 \mathrm{ft}$.

The lodgepole pine model represents an improvement over that for Douglas fir but currently indicates a too rapid rate of growth above age 70 years. It may be necessary to use two regressions of d.b.h. on age which merge at a d.b.h. of 7 inches, for example.

It is hoped that during the next year the necessary field data will be secured for refinement and further testing of the lodgepole pine model.

\section{Limitations}

The data used in developing the models are the best available but much more information is needed to confirm and extend the relationships observed in this study. Some of the observations made after testing of alternatives with the models can only be verified after many years of study of growth of actual stands. The models apply only within the limits indicated by variations in the basic data and obviously represent a substantial simplification of the situation in Nature. 


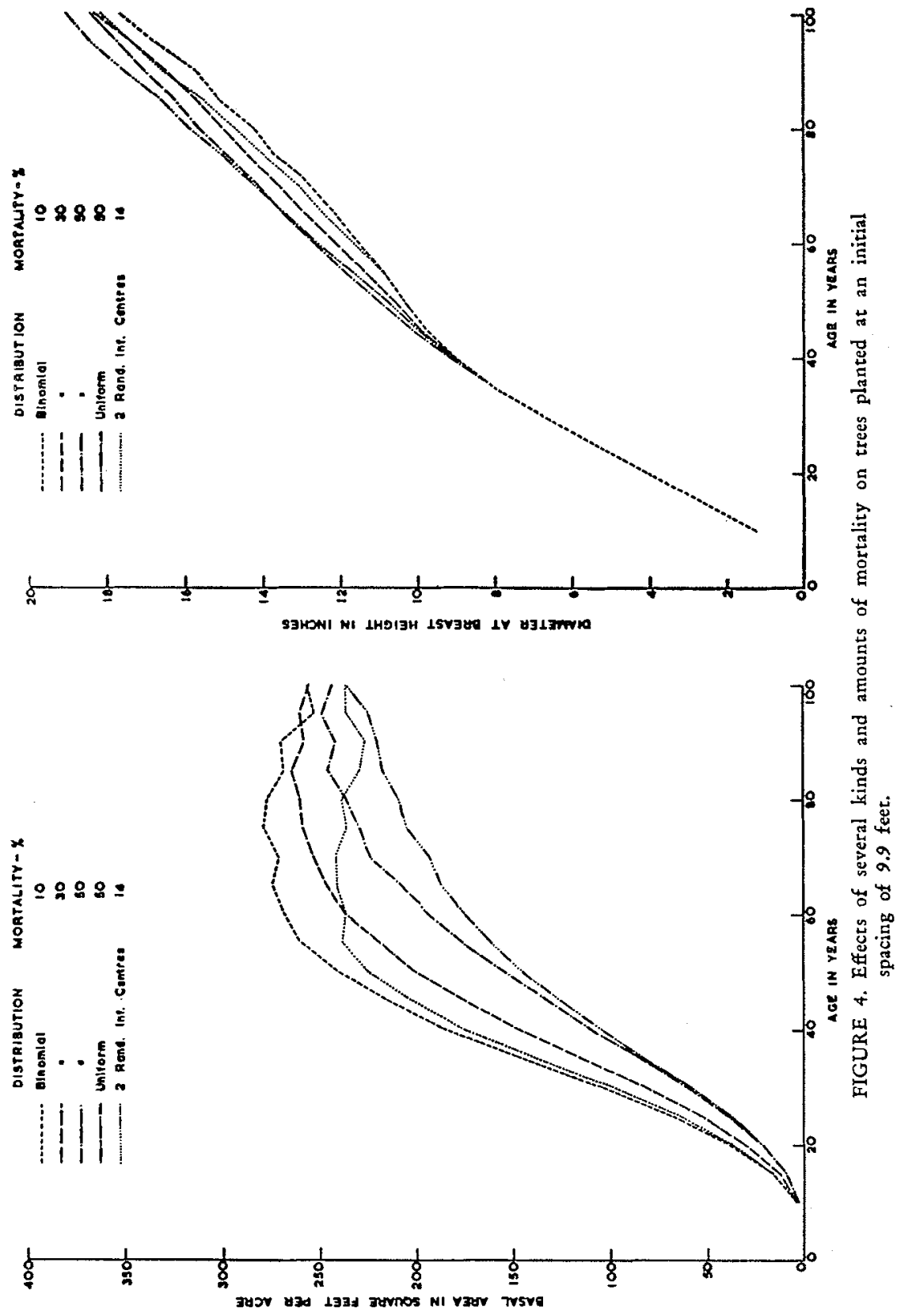




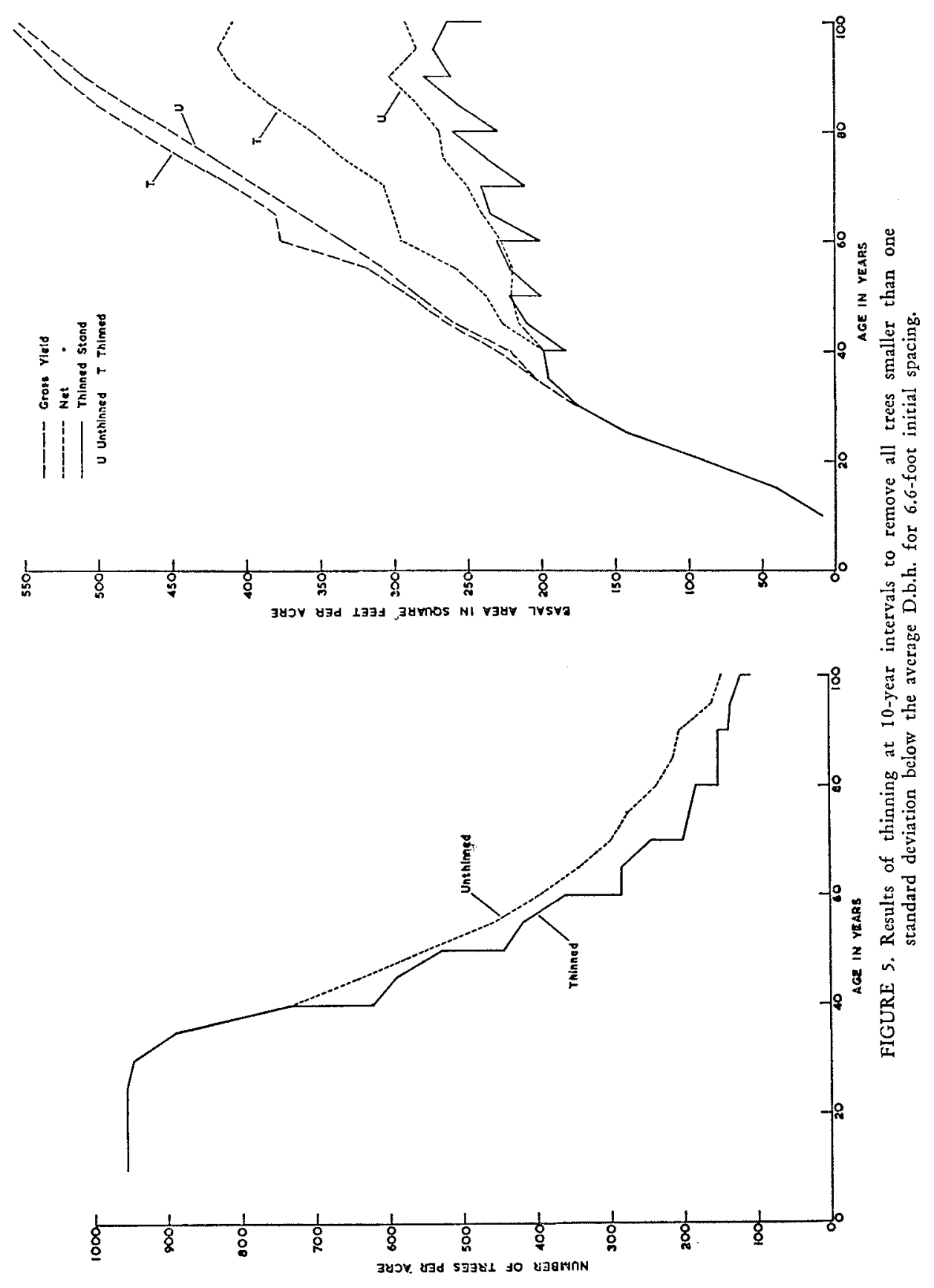




\section{CONCLUSIONS}

The stand models described here for Douglas fir and lodgepole pine permit rapid and inexpensive comparisons of a large number of alternatives related to initial spacing, and removal of trees by natural mortality or thinning. Similar models based upon measurements of open-grown trees of other species also could contribute much to improvement of forest management.

\section{Literature Cited}

BAILEY, G. R. 1964. Effect of competition on the growth and crown form of lodgepole pine. Univ. of B.C., Fac. of For., M.F. thesis, 128 p.

DAHMS, W. G. 1964. Gross and net yield tables for lodgepole pine. U.S.F.S., P.N.W. For. and Range Expt. Stn., Portland, Research Paper P.N.W.-8, 14 p.

NEWNHAM, R. M. 1964. The development of a stand model for Douglas fir. Univ. of B.C., Fac. of For., Ph.D. thesis, 201 p. Litho.

SMITH, J. H. G. 1963. Analysis of crown development can establish biological and economic limits to growth of trees and stands. Commonwealth For. Rev., 42(1): 27-33.

SMITH, J. H. G. 1964. Forecasting stand development from stem analysis. Proc. Soc. Amer. For., 1963, 31-4.

SMITH, J. H. G. and R. E. BREADON, 1964. Combined variable equations and volumebasal area ratios for total cubic foot volumes of the commercial trees of B.C. For. Chron. $40(2): 258-61$.

SMITH, J. H. G., KER, J. W. and J. CSIZMAZIA, 1961. Economics of reforestation of Douglas fir, western hemlock, and western red cedar in the Vancouver Forest District. Univ. of B.C. Fac. of For., For. Bull. No. 3, 144 p.

\section{Continued from page 493}

\section{REFERENCES}

CROSSLEY, D. I. 1956. The possibility of continuous planting of white spruce throughout the frost-free period. Canada Forestry Branch (For. Res. Div.) Tech. Note No. 32; 31 p. LAING, E. V. 1932. Studies on Tree Roots. Forestry Comm. London. Bull. No. 13. 72 p. + plates.

MULLIN, R. E. 1963. Planting check in spruce. For. Chron. 39 (3): 252-259.

SMITH, J. H. G. and J. WALTERS, 1963. Planting check (reduction in height growth) of planted Douglas fir seedling. Fac. of For., Univ. of British Columbia. Res. Notes No. 43.4 p.

STIELL, W. M. 1960. A co-operative experimental planting project in Ontario. Woodlands Review, Pulp \& Paper Magazine of Canada 61 (2): 3-6.

WEATHERELL, J. 1953. The checking of forest trees by heather. Forestry XXVI (1):37-40.

WHITE, D. P. 1960. Effect of fertilization and weed control on the establishment, survival and early growth of spruce plantations. 7th International Congress of Soil Science. Madison, Wisc., Transactions Vol. III. 355-362. 


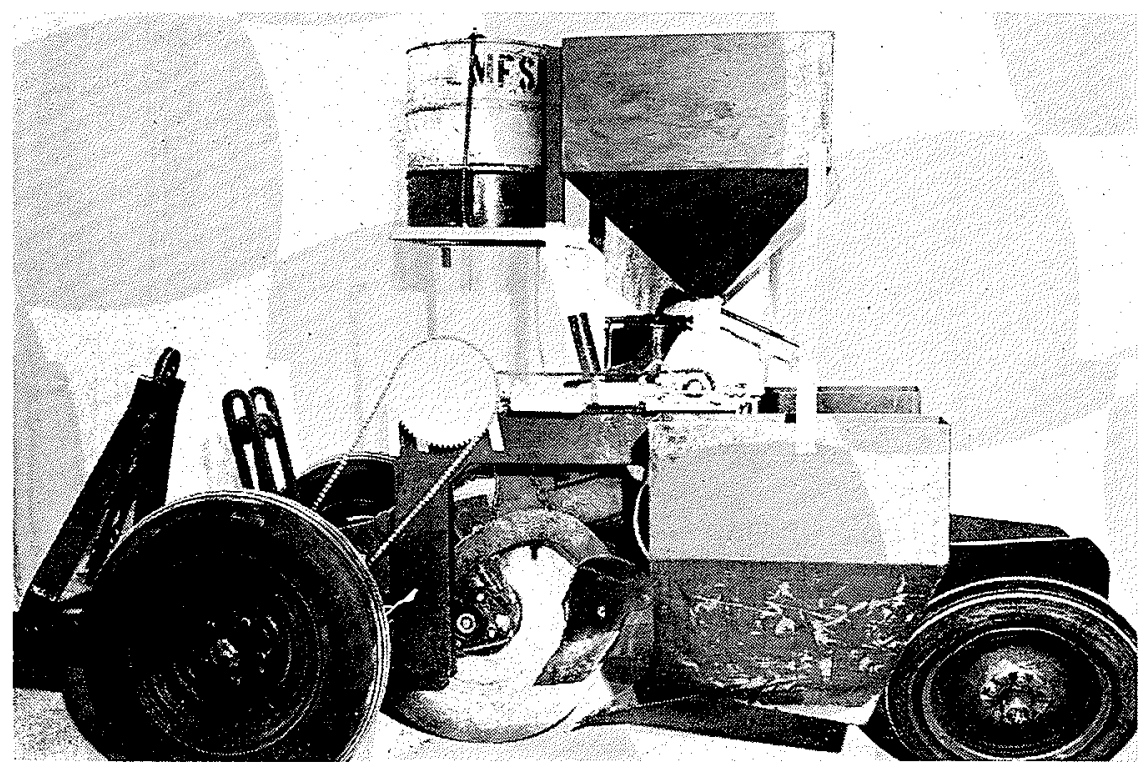

Figure 1 - Side view of Lowther tree planter with attachments for dispensing insecticides.
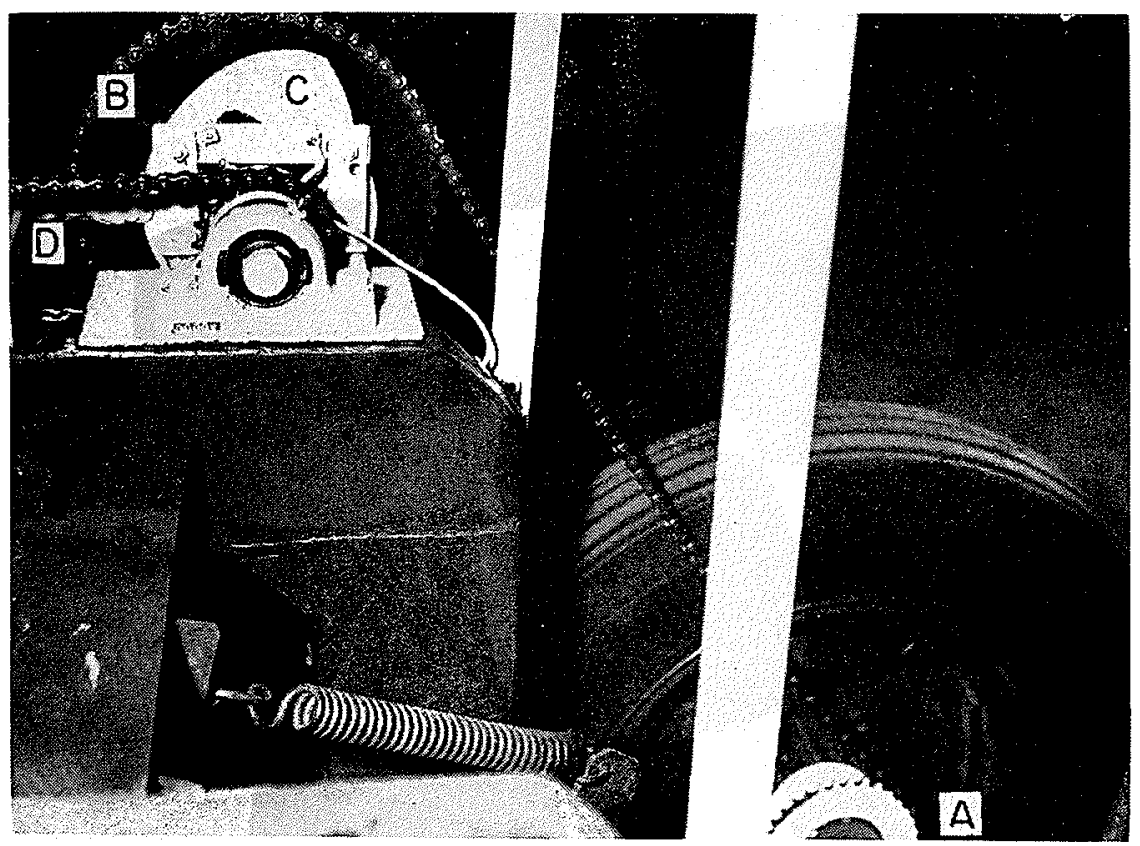

Figure 2 - Chain drive and timing apparatus: (A) 35-tooth sprocket; (B) 60-tooth sprocket; (C) cam; (D) cam-follower rod, 


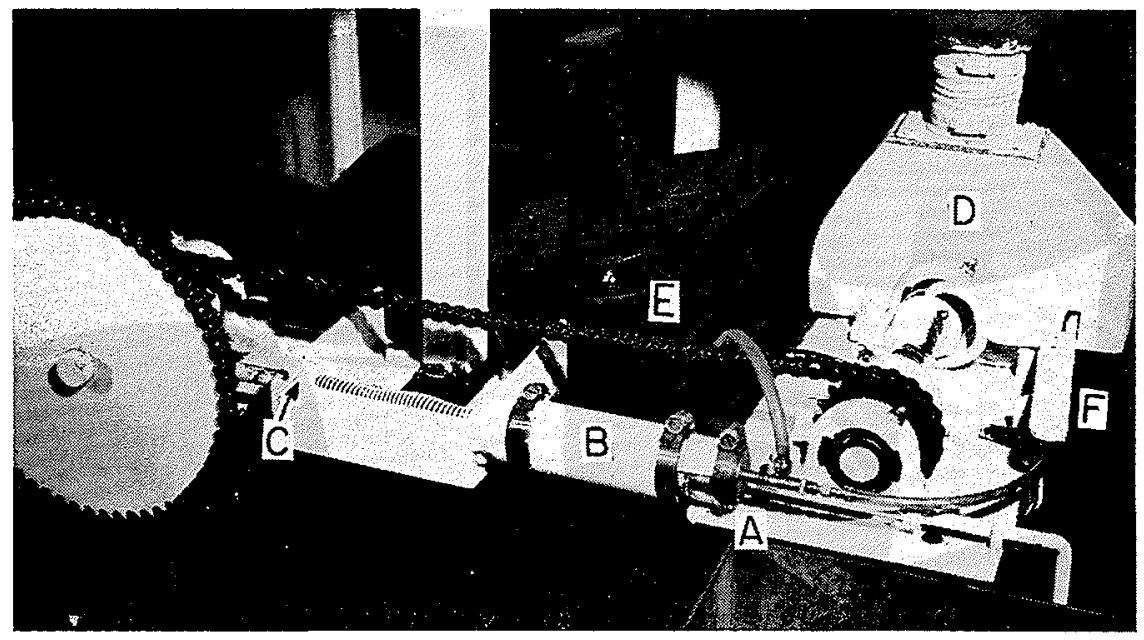

Figure 3 -- Side view of liquid and granule dispensers: (A) brass syringe and Cornwall LuerLok adapters; (B) plastic hose, covering plunger; (C) cam-follower rod collar; (D) rotating drum assembly; (E) chain drive for drum assembly; (F) disengaging mechanism for granule dispenser.

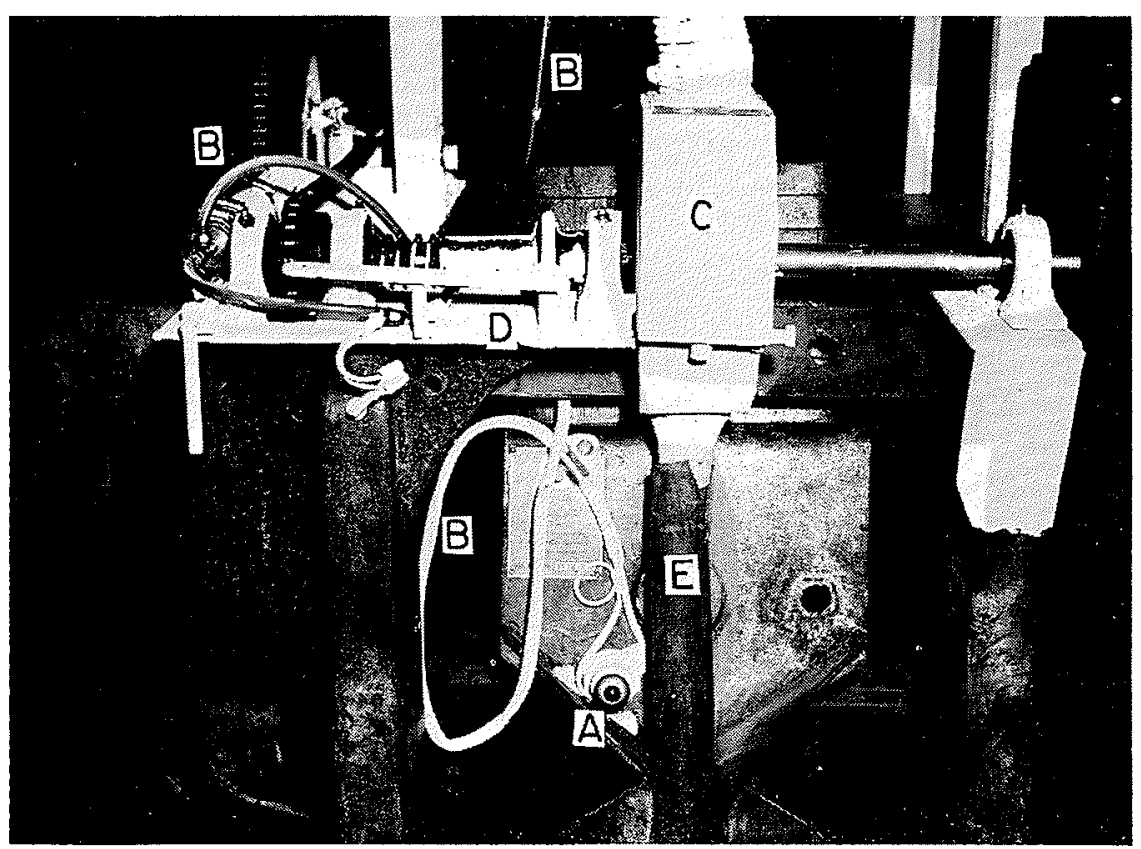

Figure + - End view of liquid and granule dispensers and signal light: (A) warning light; (B) liquid dispensing tubing; (C) rotating drum assembly; (D) disengaging mechanism for granule dispensers; (E) granule dispensing hose. 